\title{
Assessment of chemiluminescence and PCR effectiveness in relation to conventional serological tests for the diagnosis of Chagas' disease
}

\author{
Avaliação da eficiência da quimiluminescência e PCR em relação aos testes \\ sorológicos convencionais para o diagnóstico da doença de Chagas
}

\author{
Aulísia Maria Vieira Duarte ${ }^{1}$, Hélida Monteiro de Andrade ${ }^{2}$, \\ Semíramis Jamil Hadad do Monte ${ }^{2}$, Vicente de Paulo Coelho Peixoto de Toledo ${ }^{1}$ \\ and Tânia Mara Pinto Dabés Guimarães ${ }^{1}$
}

\begin{abstract}
While testing 414 sera for the diagnosis of Chagas' disease, the conventional reactions of indirect hemagglutination, indirect immunofluorescence and the immunosorbent assay showed a sensitivity of 95.7\%, 100\% and 98.2\% and a specificity of 98\%, 98\% and 96.4\%, respectively, and an excellent association using Fisher's exact test. Chemiluminescence presented 100\% sensitivity and $89.6 \%$ specificity, while PCR showed $100 \%$ specificity and $1.2 \%$ sensitivity. It is believed that the three conventional serological reactions are still adequate for diagnosing Chagas' disease.
\end{abstract}

Key-words: Chagas' disease. Diagnosis. Serology. Chemiluminescence. PCR.

\section{RESUMO}

No exame de 414 soros, para o diagnóstico da doença de Chagas, as reações convencionais de hemaglutinação indireta, imunofluorescência indireta e o ensaio imunoenzimático mostraram, respectivamente, uma sensibilidade de 95,7\%, 100\% e 98,2\% e uma especificidade de 98\%, 98\% e 96,4\% e excelente associação usando teste exato de Fisher. A quimioluminescência apresentou 100\% de sensibilidade, 89,6\% de especificidade e a PCR 100\% de especificidade e 1,2\% de sensibilidade. Acreditase que as três reações sorológicas convencionais ainda são suficientes para o diagnóstico da doença de Chagas.

Palavras-chaves: Doença de Chagas. Diagnóstico. Sorologia. Quimioluminescência. PCR.

Chagas' disease or American trypanosomiasis is an endemic infection of gradual evolution caused by the intracellular protozoa Trypanosoma cruzi. Diagnosis of chagasic patients has been made through parasitological and/ or serological methods like indirect hemagglutination (IH), indirect immunofluorescence (IFA) and indirect enzymelinked immunosorbent assay (ELISA). Other reactions such as chemiluminescence ${ }^{1}$, agglutination in gel ${ }^{12}$, lysis mediated by complement ${ }^{8}$ and trans-sialidase inhibition ${ }^{310}$ can be used. Chemiluminescence has not, however, been used for the diagnosis of Chagas' disease as it is still being standardized.

Current legislation ${ }^{11}$ recommends screening tests for Chagas' disease in blood banks, but not in laboratories, using at least two methods with different methodological principles due to the false-positive and false-negative reactions found in different methodologies. IH, IFA and ELISA are considered typical reactions and are currently used. Technical scientific advances have made new tests and methods available. The suggestion to evaluate chemiluminescence and PCR as complementary tests for introduction in laboratory routines for the diagnosis of Chagas' disease, as well as their comparison with conventional methodologies is relevant, because of the need to find out precisely what their specificity, sensitivity and efficiency are. These three aspects are of major importance as they reflect not only on the results, but also on the prospect of clarifying doubts that have been raised by

\footnotetext{
1. Department of Clinical and Toxicological Analysis of the Faculty of Pharmacy of the Federal University of Minas Gerais, Belo Horizonte, MG. 2. Laboratory of Immunogenetic and Molecular Biology of the Parasitology and Microbiology Department of the Federal University of Piauí, Teresina, PI.

Address to: Dr. Vicente de Paulo Coelho Peixoto de Toledo. Department of Clinical and Toxicological Analysis, Faculty of Pharmacy of the Federal University of Minas Gerais. Av. Antônio Carlos 6627, 31270-010 Belo Horizonte, MG, Brasil.

Telefax: 5531 3499-6886

e-mail: toledovp.bh@terra.com.br

Recebido para publicação em 4/3/2005

Aceito em 30/5/2006
} 
cross-reactions with antibodies from carriers of chronic diseases and also the confirmation of indeterminate results obtained in conventional serological reactions.

A total of 414 volunteers, male and female, aged between 10 and 80 years old, residents of urban and rural areas, took part in this study, which was conducted between October 2000 and January 2002. These individuals came from the municipalities of Itabira $(\mathrm{n}=82)$, ferros $(\mathrm{n}=229)$ and carbonita $(\mathrm{n}=103)$ in the state of Minas Gerais, Brazil. Ninety-nine individuals had characteristic symptoms of the infection, such as cardiological $(\mathrm{n}=79)$, digestive $(\mathrm{n}=15)$ and cardiodigestive alterations $(\mathrm{n}=5)$, in addition to being seropositive. Sixty-three volunteers showed no symptoms, even though they were seropositive, and eighteen experienced no symptoms and their sera were classified as indeterminate. The control group was made up of two hundred and thirty four healthy seronegative volunteers who exhibited no symptoms of Chagas' disease and were residents of the same cities as the study group.

All samples were tested by three different serological tests: IFA, IH and ELISA, carried out according to the manufacturer's instructions (Biolab-Mérieux SA - Rio de Janeiro, Brazil). The patient was classified as positive if at least two tests were positive; negative if three tests results were negative and indeterminate if results did not fit any of the previous criteria. In order to assess reproducibility, 48 (11.6\%) samples out of a total of 414 were selected at random. The diagnostic kits used were the same as for previous testing. Positive and negative control sera were introduced in all the reactions. Chemiluminescence was performed using the IMMULITE $®$ Chagas IgG commercial kit (DPC-MedLab - Brazil) and IMMULITE system (DPC-MedLab). DNA samples from infected individuals were subjected to PCR, with the pair of primers 121 and 122 which amplified a $330 \mathrm{pb}$ fragment of the conserved micro region of the parasite T. cruzi kDNA minicircles ${ }^{6}$.

According to the criteria used in this work, it was observed that out of a total surveyed population of 414 individuals 236 (57\%) of the samples tested negative, 161 (39\%) positive and 17 (4\%) were indeterminate. Chemiluminescence presented the highest number of seropositive and indeterminate individuals and the lowest number of seronegative results. In relation to sensitivity, both chemiluminescence and IFA presented the highest (100\%) value, but for specificity and efficiency, they presented the lowest values in comparison with conventional methods. Analysis of the Kappa index for the reproducibility of the 48 (11.6\%) samples chosen at random showed that all the reactions, IH, IFA and ELISA presented an excellent agreement. For IH, the Kappa index was equal to 1,000 and for IFA and ELISA, 0.908 and 0.905 respectively. The chemiluminescence reaction also demonstrated good agreement with the Kappa index of 0.751 $(\mathrm{p}<0.001)$.

With respect to PCR, amplification was performed for the 414 blood samples tested in this study. After amplification, out of the 161 samples which had been confirmed positive, two tested positive with a sensitivity value of $1.2 \%$ and $100 \%$ specificity.

There was a prevalence of negative individuals (57\%) over those who were positive (39\%). The percentage of indeterminate cases ( $4 \%$ ) could be significant when a larger population is taken into account. It is worth highlighting that this indeterminate serological group is a real concern for blood banks. It was observed that the $95.7 \%$ sensitivity value found in $\mathrm{IH}$ is situated between the values of $91.2 \%{ }^{13}$ and $97 \%{ }^{15}$ previously described, whereas the $98 \%$ specificity found in this study is inferior to the $100 \%$ previously described ${ }^{131415}$. No indeterminate reaction was found in the indirect immunofluorescence, presenting 100\% sensitivity, 98\% specificity and $98.8 \%$ efficiency. These results are similar to those of other authors who showed $100 \%$ sensitivity and $95 \%$ specificity ${ }^{15}$. With respect to ELISA, 244 samples tested negative, 165 positive and 5 indeterminate with a value of $98.2 \%$ for sensitivity and $96.4 \%$ and $97.1 \%$ for specificity and efficiency, respectively. In the present study, chemiluminescence with recombinant antigen was used (DPC-Med-lab kit). Many authors suggest the use of purified antigens of $T$. cruzi epimastigotes or recombinant antigens in order to reduce cross-reaction ${ }^{914}{ }^{15}$. Chemiluminescence presented the lowest specificity and efficiency: $89.6 \%$ and $93.7 \%$, respectively. However, it presented excellent sensitivity: $100 \%$. This can be observed in Table 1 . The use of chemiluminescence as a way to diagnosis Chagas' disease has not been used in many studies. Results of indeterminate cases have not been found by chemiluminescence, contrary to that which can be observed with the IH, IFA and ELISA reactions, possibly due to the use of trypomastigote antigens.

Table 1-Serological tests for Chagas' disease and rates of sensitivity $(S)$, specificity (Sp) and efficiency (Ef) in 414 human sera.

\begin{tabular}{|c|c|c|c|c|c|c|c|c|c|}
\hline \multirow[b]{3}{*}{ Serological method } & \multicolumn{6}{|c|}{ Serological results } & \multirow{3}{*}{$\begin{array}{l}S \\
\%\end{array}$} & \multirow{3}{*}{$\begin{array}{c}\mathrm{Sp} \\
\%\end{array}$} & \multirow{3}{*}{$\begin{array}{r}\mathrm{Ef} \\
\%\end{array}$} \\
\hline & \multicolumn{2}{|c|}{ negative i } & \multicolumn{2}{|c|}{ ndeterminate } & \multicolumn{2}{|c|}{ positive } & & & \\
\hline & $\mathrm{n}^{\circ}$ & $\%$ & $\mathrm{n}^{\circ}$ & $\%$ & $\overline{\mathrm{n}^{\circ}}$ & $\%$ & & & \\
\hline $\mathrm{IH}$ & 251 & 60.6 & 5 & 1.2 & 158 & 38.2 & 95.7 & 98.0 & 96.8 \\
\hline IFA-IgG & 245 & 59.4 & 0 & 0.0 & 169 & 40.8 & 100.0 & 98.0 & 98.8 \\
\hline ELISA & 244 & 58.9 & 5 & 1.2 & 165 & 39.9 & 98.2 & 96.4 & 97.1 \\
\hline Chemiluminescence & 224 & 54.1 & 8 & 1.9 & 182 & 44.0 & 100.0 & 89.6 & 93.7 \\
\hline
\end{tabular}

IH: indirect hemagglutination technique; IFA: indirect immunofluorescence reaction; ELISA: enzyme-linked immunosorbent assay.

For PCR, only 2 positive results were found in 162 samples of chagasic patients through traditional serology, where specificity for PCR was $100 \%$ and sensitivity was $1.2 \%$. Some authors have found low sensitivity through the hot-start technique with positive results below $60 \%^{37}$. It has already been demonstrated that PCR is not appropriate as the sole diagnosis method, rather as a complement to serology, particularly in the case of indeterminate patients ${ }^{17}$.

The results obtained in this study show that the three traditional serological reactions are still sufficiently effective for the diagnosis of Chagas' disease. This is due to the fact that, up to now, no other methodology has been standardized with higher rates than those found for these methods, i.e. sensitivity and specificity close to $100 \%$. Furthermore, it was shown that IFA was the most appropriate reaction for routine diagnoses. Considering this fact, clinical laboratories should be using IFA to clarify doubtful cases, since it showed 100\% sensitivity and $98 \%$ specificity. 


\section{ACKNOWLEDGEMENTS}

The authors are grateful to Dr João Carlos Pinto Dias, for facilitating access to the patients of the Hospital de Carbonita, to Dr Cássio Lúcio Vieira Duarte, for the selection of chagasic patients from the municipalities of Ferros and Carbonita and to MedLab/ DPC and BioMerrieux SA for supplying the kits used in this study.

\section{REFERENCES}

1. Almeida IC, Rodrigues EG, Travassos LR. Chemoluminescent immunoassays: discrimination between the reactivates of natural and human patients antibodies from eukaryotic pathogens, Trypanosoma cruzi and Paracoccidioides brasiliensis. Journal of Clinical Laboratory Analisis 8: 424-431, 1994.

2. Araújo FMG, Bahia MT, Magalhães NM, Martins-Filho 0. Follow-up of experimental chronic Chagas' disease in dogs: use of polymerase chain reaction (PCR) compared with parasitological and serological methods. Acta Tropica 81: 21-31, 2002.

3. Britto C, Cardoso MA, Vanni CMM, Hasslocher-Moreno A, Xavier S. Polymerase chain reaction detection of Trypanosoma cruzi in human blood samples as a tool for diagnosis and treatment evolution. Parasitology 110: 241-247, 1995.

4. Brito C, Cardoso MA, Wincker P, Morel CM. A simple protocol for the physical cleavage of Trypanosoma cruzi kinetoplast DNA present in blood samples and its use in polymerase chain reaction (PCR)-based diagnosis of chronic Chagas' disease. Memórias do Instituto Oswaldo Cruz 88: 171-172, 1993.

5. Buchovsky AS, Campetella 0, Russomando G, Franco L, Oddone R. Transsialidase inhibition assay, a highty sensitive and specific diagnostic test for Chagas' disease. Clinical Diagnosis Laboratory Immunology 8: 187189, 2001.

6. Gomes LM, Macedo AM, Vago AR, Pena SDJ. Trypanosoma cruzi: optimization of polymerase chain reaction for detection in human blood. Experimental Parasitology 88: 28-33, 1998.

7. Junqueira ACV, Chiari E, Wincker P. Comparison of the polymerase chain reaction with two classical parasitological methods for the diagnosis of Chagas' disease in an endemic region of north-eastern Brazil.
Transaction Royal Society of Tropical Medicine and Hygiene 90: 129-132, 1996.

8. Krettli AV, Brenner Z. Resistance against Trypanosoma cruzi associated to anti-living trypomastigote antibodies. Journal Immunology 129: 20092012, 1982.

9. Krieger MA, Almeida E, Oelemann W, Lafaille JJ, Pereira JB, Carvalho MR, Goldenberg S. Use of recombinant antigens for the accurate immunodiagnosis of Chagas' disease. The American Journal of Tropical Medicine and Hygiene 46: 427-434, 1992.

10. Leguizamon MS, Russomando G, Luquetti A, Rassi A, Almiron M. Longlasting antibodies detected by a trans-sialidase inhibition assay of sera from parasite-free, serologically cured chagasic patients. Journal Infectious Diseases 5: 1272-1275, 1997.

11. Ministério da Saúde. Portaria n. 1376/GM de 19 novembro 1993. Aprova alterações na portaria $721 / \mathrm{GM}$, de 09/08/89, que aprova normas técnicas para coleta, processamento e transfusão de sangue, componentes e derivados e dá outras providências. Diário oficial da República Federativa do Brasil, 02 dezembro de 1993. Brasília, 1993.

12. Rabello A, Luquetti AO, Moreira EF, Gadelha MF, Santos JA. Serodiagnosis of Trypanosoma cruzi infection using the new particle gel immunoassayID PaGIA Chagas. Memórias do Instituto Oswaldo Cruz 94: 77-82, 1999.

13. Sáez-Alquézar A, Luquetti A0, Borges-Pereira J, Moreira EF, Gadelha MF. Estudo multicêntrico: avaliação do desempenho de conjuntos diagnósticos de hemaglutinação indireta, disponíveis no Brasil, para o diagnóstico sorológico da infecção pelo Trypanosoma cruzi. Revista de Patologia Tropical 26: 343-374,1997.

14. Teixeira ARL,Vexenat AC. O real significado de exames sorológicos no diagnóstico de doenças endêmicas. Revista da Sociedade Brasileira de Medicina Tropical 29: 379-382, 1996.

15. Teixeira MGM, Borges-Pereira J, Peralta JM. Evaluation of serological tests applied for the detection of Trypanosoma cruzi infection. Revista Brasileira de Patologia Clínica 30:3, 1994.

16. Wincker P, Britto C, Borges-Pereira J, Cardoso MA, Oeleman W, Morel CM. Use of a simplified polymerase chain reaction procedure to detect Trypanosoma cruzi in blood samples from chronic chagasic patients in a rural endemic area. The American Journal of Tropical Medicine and Hygiene 51: 771-777, 1994.

17. Wincker P, Telleria J, Bosseno MF, Cardoso MA, Marques P. PCR-based diagnosis for Chagas' disease in Bolivian children living in an active transmission area: comparison with conventional serological and parasitological diagnosis. Parasitology 114: 367-373, 1996. 